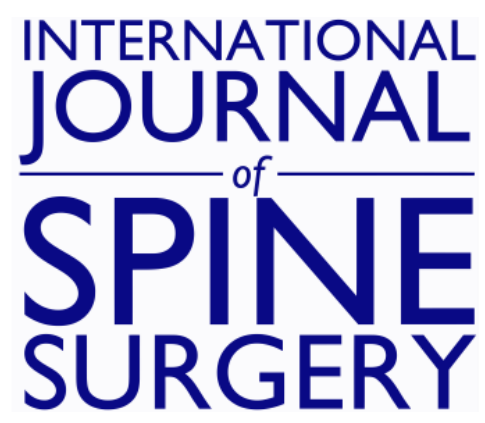

\title{
2021 Position Statement From the International Society for the Advancement of Spine Surgery on Cervical and Lumbar Disc Replacement
}

Gregory D. Schroeder, Alexander R. Vaccaro, Srikanth N. Divi, Ariana A. Reyes, Dhruv K.C. Goyal, Frank M. Phillips and Jack Zigler

Int J Spine Surg 2021, 15 (1) 37-46

doi: https://doi.org/10.14444/8004

http://ijssurgery.com/content/15/1/37

This information is current as of April 26, 2023.

Email Alerts Receive free email-alerts when new articles cite this article. Sign up at: http://ijssurgery.com/alerts 


\title{
2021 Position Statement From the International Society for the Advancement of Spine Surgery on Cervical and Lumbar Disc Replacement
}

\author{
GREGORY D. SCHROEDER, MD ${ }^{1}$ ALEXANDER R. VACCARO, MD, PHD, MBA, ${ }^{1}$ SRIKANTH N. DIVI, \\ MD ${ }^{2}$ ARIANA A. REYES, BS, ${ }^{1}$ DHRUV K.C. GOYAL, BA, ${ }^{1}$ FRANK M. PHILLIPS, MD, ${ }^{3}$ JACK ZIGLER, \\ $\mathrm{MD}^{4}$ \\ ${ }^{1}$ Rothman Institute at Thomas Jefferson University Hospital, Philadelphia, Pennsylvania, ${ }^{2}$ University of Chicago Medical Center, Chicago, Illinois, ${ }^{3}$ Midwest \\ Orthopaedics at Rush, Rush University Medical Center, Chicago, Illinois, ${ }^{4}$ Texas Back Institute, Plano, Texas
}

\section{INTRODUCTION}

Cervical and lumbar degenerative disc disease are well-known causes of neck and back pain and associated radiculopathy in spine patients. The estimated 1-year incidence rate of neck pain and any episode of lower back pain is $10.4 \%$ to $21.3 \%{ }^{1,2}$ and $1.5 \%$ to $36 \%,{ }^{3}$ respectively. Previous reports demonstrate significant socioeconomic effects of these common conditions. ${ }^{4,5}$ Initial conservative treatment and ultimately fusion procedures or disc replacement are potential options for treatment of recalcitrant cervical and lumbar degenerative disc disease. Despite past reports of improved clinical outcomes with cervical and lumbar fusion procedures, there continue to be concerns of limiting motion at the affected segment and development of adjacent-segment degeneration and disease. Hilibrand et $\mathrm{al}^{6}$ demonstrated that adjacent-segment disease occurred at a rate of $2.9 \%$ per year during the 10-year postoperative period following anterior cervical fusion. Other studies have reported even higher adjacent-segment degeneration and disease rates of $36 \%{ }^{7}$ and $50 \%{ }^{8}$ in the cervical spine. Past reports illustrate a wide range of the incidence rate $(2.62 \%$ to $34 \%)$ of adjacent segment degeneration and disease after lumbar fusion. ${ }^{9-11}$ These results led to the subsequent development of cervical and lumbar arthroplasty devices.

Currently, there are 8 Food and Drug Administration (FDA)-approved cervical and 3 FDAapproved lumbar total disc replacement (TDR) devices, not all of which are still commercially available. The aim of this review is to discuss the results of long-term follow-up studies, recent meta- analyses, and potential complications with cervical and lumbar TDR devices.

\section{CERVICAL TOTAL DISC REPLACEMENT}

\section{Historical Background}

The first use of cervical TDR (cTDR) dates back to the 1960s. ${ }^{12}$ Currently, 8 devices have been approved by the FDA for single-level use in cervical arthroplasty: Prestige ST (Medtronic, Minneapolis, MN), ProDisc-C (Centinel Spine, LLC, West Chester, PA), BRYAN (Medtronic), SECURE-C (Globus Medical, Audubon, PA), PCM (NuVasive, Inc, San Diego, CA), Mobic-C (Zimmer Biomet, Warsaw, IN), Prestige LP (Medtronic), and M6 cervical disc (Orthofix, Lewisville, TX). Mobic-C and Prestige LP are also approved for 2-level use. The M6 device has most recently received premarket approval $^{13(\mathrm{p} 6)}$ and the Simplify disc has completed 1- and 2-level enrollment and is approaching FDA determination. The initial FDA investigational device exemption (IDE) trials for the currently approved cTDR devices demonstrated similar or greater improvement in outcomes of patients in the device group compared to anterior cervical discectomy and fusion (ACDF). ${ }^{14-21}$ Similarly, metaanalyses of the these IDE trials illustrated similar improved outcomes with cTDR. ${ }^{22,23}$

\section{Long-Term Follow-Up and Recent Meta-Analyses}

Initial prospective, randomized controlled IDE trials have demonstrated equivalent or improved functional outcome results of cTDR compared to ACDF. ${ }^{14-21}$ Mid- and long-term follow-up have 
also demonstrated the overall positive success of arthroplasty compared to ACDF. ${ }^{24-28}$ In an 8-year follow-up study of 21 patients, Quan et $\mathrm{al}^{24}$ reported that the majority of patients with the BRYAN disc continued to have favorable results. Burkus et $\mathrm{al}^{25}$ reported at 36 and 60 months the arthroplasty group had statistically significant better neck disability index scores $(P=.008$ and .022 , respectively) as wel as neurologic recovery $(P=.004$ and .051 , respectively) when compared with an ACDF. Coric et $\mathrm{al}^{26}$ reported significant, sustained improvement in range of motion in patients with cTDR (BRYAN disc or Kineflex-C) compared to ACDF at 4-year follow-up. In a 5-year follow-up study, Zigler et $\mathrm{al}^{27}$ demonstrated that both groups (Prodisc-C and ACDF) had statistically significant improved clinical outcomes compared to baseline but patients with Prodisc-C had greater improvement in reported neck pain. At 4-year follow-up, Delamarter et $\mathrm{al}^{28}$ reported improved visual analogue scale (VAS) neck score in patients with Prodisc-C compared to ACDF.

Recently, longer-term follow-up (5 years or greater) studies continue to demonstrate successful results of arthroplasty compared to ACDFs, with lower rates of reoperation. ${ }^{29-35}$ Janssen et $\mathrm{al}^{29}$ reported that both groups (Prodisc- $\mathrm{C}$ and ACDF) continued to have improved patient satisfaction with surgery and neurologic status at 7-year followup. Both groups reported similar positive outcomes; however, fewer patients in the Prodisc group (7\%) had secondary surgery compared to those with ACDF (18\%). ${ }^{29}$ In a 10 -year follow-up of the IDE study, Gornet et $\mathrm{al}^{30}$ reported stable results for the Prestige LP group with patient-reported outcomes, neurological status, and overall success. The authors also reported that the average motion at the index and adjacent level was maintained at 10-year followup and concluded that the device continued to have safe and effective results. ${ }^{30}$ Lavelle et $\mathrm{al}^{31}$ reported 10-year outcomes for patients with the BRYAN cervical disc. The authors reported statistically significant improvement in overall success $(81.3 \%$ versus $66.3 \%$ ) and neck and disability index (NDI) score in patients with cTDR compared to the ACDF group. ${ }^{31}$ Although the results were not shown to be statistically significant, patients with the BRYAN disc had a lower rate of secondary surgeries compared to those with ACDFs $(9.7 \%$ versus $15.8 \% ; P=.146) .^{31}$ Phillips et al ${ }^{32}$ reported 7-year follow-up of the FDA IDE trial for the PCM device demonstrated greater improvement with NDI, VAS neck pain, physical component score and mental component score of the Short Form-12 than with the control ACDF. The authors also reported decreased trends in secondary surgeries $(3.6 \%$ versus $7.6 \%){ }^{32}$ Hisey et $\mathrm{al}^{33}$ reported, at 5year follow-up, similar improvements in NDI, VAS neck and arm pain, and Short Form-12 scores for both groups (Mobic-C and ACDF). Additionally at 7-year follow-up for Mobic-C, Radcliff et $\mathrm{al}^{36}$ reported improvement in patient-reported outcomes (NDI, VAS neck/ arm pain, Short Form-12 mental and physical component scores) for both the cTDR and ACDF group. The authors reported a statistically significant greater patient satisfaction in the cTDR group compared to ACDF. ${ }^{36}$ Burkus et $\mathrm{al}^{34}$ reported maintained or improved neurologic status in patients with cTDR (Prestige disc) compared to ACDF from a 5- to 7-year period. Vaccaro et $\mathrm{al}^{35}$ reported statistical superiority in overall success $(79.2 \%$ and $63.6 \%)$ and patient satisfaction $(96 \%$ versus $88.8 \%$ ) in the SECURE-C investigational group compared to ACDF at 7-year follow-up.

Previously in a meta-analysis, McAfee et $\mathrm{al}^{22}$ demonstrated that patients who had undergone arthroplasty achieved greater overall clinical success compared to ACDF patients $(77.6 \%$ versus $70.8 \%)$. In a meta-analysis of 3 FDA IDE randomized controlled trials (RCTs), Udaphyaya et $\mathrm{al}^{23}$ reported greater neurologic success and lower rate of secondary surgeries for the cTDR group compared to the ACDF group. More recently, Gao et $\mathrm{al}^{37}$ reported improved neurologic success and neck or arm pain (VAS) scores, fewer secondary surgeries, and increased motion at the index level in patients with cTDR versus ACDF. Similarly, a metaanalysis conducted by Zhang et $\mathrm{al}^{38}$ reported improved neurologic success in the arthroplasty group compared to ACDF. The authors also reported superiority in NDI, neck and arm pain (Numeric Rating Scale) scores, and fewer secondary surgical procedures at the index level. ${ }^{38}$

\section{Adjacent-Segment Disease}

Long-term follow-up has facilitated further understanding of radiographic adjacent-segment degeneration and symptomatic adjacent-segment disease with cervical arthroplasty. Phillips et $\mathrm{al}^{32}$ reported more frequent radiographic adjacent-segment degeneration with ACDF compared to cTDR at 7 -year follow-up. Hisey et $\mathrm{al}^{33}$ demonstrated that 
adjacent-segment degeneration at the superior level was significantly lower for cTDR patients than ACDF at 5-year follow-up. Similarly, Burkus et al ${ }^{34}$ reported lower rates of additional adjacent-level surgeries in the cTDR group compared to ACDF at 7-year follow-up. Vaccaro et $\mathrm{al}^{35}$ also demonstrated that fewer SECURE-C patients (17\%) reported symptoms related to the adjacent level(s) compared to ACDF patients $(37.5 \%)$ at 7 -year follow-up. Janssen et $\mathrm{al}^{29}$ reported fewer surgical procedures involving the adjacent level(s) in the ProDisc-C group compared to the ACDF group at 7-year follow-up. At 10-year follow-up, results from Lavelle et $\mathrm{al}^{31}$ and Gornet et $\mathrm{al}^{30}$ also demonstrated lower rates of revision surgeries for the adjacent level in the cTDR group compared to the ACDF groups (BRYAN and Prestige LP, respectively).

In a review of 52,395 cases, Kelly et $\mathrm{al}^{39}$ reported that short-term readmission was lower in the cTDR group $(P=.048)$ as well as secondary surgery in the cTDR compared to the ACDF group within 90 days of surgery $(2.04 \%$ versus $3.35 \%, P=.015)$; however, there was no difference in rates at long-term followup $(1,3,5$ years postoperatively) between the 2 cohorts. While the authors concluded that there was no protective benefits for single-level degenerative disease with cTDR compared to ACDF, this is may be secondary to the significant limiation of this being a large database study that will only identify long-term issues in patients who undergo a revision at a nonfederal hospital in California. Patients who have revisions at any other hospital system will not be identified. ${ }^{39}$

Various meta-analyses have been conducted in attempts to further clarify potential benefits of arthroplasty compared to ACDF. ${ }^{40-42}$ Verma et $\mathrm{al}^{40}$ reported that although there were more patients in the ACDF group requiring adjacent-level surgery at 2- to 5-year follow-up than in the cTDR group $(6.9 \%$ versus $5.1 \%)$, the differences in rate of reoperation between the 2 groups was not statistically significant. In a meta-analysis of 32 studies, Shriver et $\mathrm{al}^{41}$ reported an increased incidence of adjacent degeneration and disease in cervical arthroplasty with long-term (more than 2 years) follow-up. Zhu et $\mathrm{al}^{42}$ combined the results of 14 RCTs with long-term follow-up (2 to 7 years) and reported that cTDR had lower rates of adjacent segment disease and fewer reoperations at the adjacent level. Although the meta-analysis by Luo et $\mathrm{al}^{43}$ included fewer RCTs, the authors similarly concluded that cTDR had lower rates of adjacent segment disease compared to ACDF at 2-year follow-up.

\section{Approval for 2-Level Use}

In 2013, Mobic-C was approved for 2-level use. In the IDE trial conducted at 24 centers, results demonstrated significant greater overall success of 2-level total disc arthroplasty with Mobic-C over ACDF. $^{20}$ Since then, studies have demonstrated positive mid-term and long-term follow-up for 2level cervical disc arthroplasty using the Mobic-C device. ${ }^{4,45}$ In a 4-year post-hoc comparison, Bae et $\mathrm{al}^{46}$ reported that there were no statistical differences in clinical outcomes or overall success of the cTDR group compared to ACDF. In a 7-year follow-up study of the original IDE clinical trial, Radcliff et $\mathrm{al}^{36}$ demonstrated that the 2-level cTDR group had a significant improvement in NDI score, increased patient satisfaction rate, and decreased rate of reoperation at the index and adjacent level compared to ACDF.

Prestige LP is also currently approved for 2-level cervical disc arthroplasty. In the IDE RCT, Gornet et $\mathrm{al}^{47}$ demonstrated that the investigational group undergoing 2-level cervical disc arthroplasty had greater overall success than 2-level ACDF. Lanman et $\mathrm{al}^{48}$ also demonstrated that the 2-level Prestige LP group had statistically greater improvement in NDI score, neurologic status, and overall success at 7year follow-up. The investigational group also had preserved motion and fewer secondary surgeries than the ACDF group at long-term follow-up. ${ }^{48}$

\section{Devices With Recent Approval/ Currently in the FDA IDE Process}

The M6-C device recently received premarket approval in 2019. In a feasibility study, M6 demonstrated comparable results to other cTDR devices. ${ }^{49}$ This device has an artificial annular (polyethylene weave) and nuclear (viscoelastic polyurethane core) component to better mimic the natural human intervertebral disc and range of motion. ${ }^{50}$ Reyes-Sanchez et $\mathrm{al}^{51}$ demonstrated improved NDI score, neck and arm pain, and physical component score of Short Form-36 with no serious adverse events at 24 months. The authors also reported that the mean range of motion returned to approximated pretreatment levels $\left(12.2^{\circ}\right.$ versus $\left.11.1^{\circ}\right)$ by 24 months. ${ }^{51}$ Similarly, Thomas et $\mathrm{al}^{52}$ also reported improved results for 
NDI, VAS, and Short Form-36 scores in patients with the M6 device. Phillips et $\mathrm{a}^{53}$ reported 2-year results of the IDE study with significant improvement for M6-C subjects, compared to ACDF controls, in overall Short Form-36 PCS scores and Neck and Arm Pain scores. Significantly fewer M6C subjects utilized pain medication or opioids at 24 months as compared to ACDF controls. Range of motion was maintained in M6-C subjects. Neck Disability Index improvement, subsequent surgical interventions, dysphagia rates, and serious adverse events were comparable between groups.

The Simplify Disc ${ }^{\mathrm{TM}}$ has recently received FDA approval for single-level use. Early results from Geisler et $\mathrm{al}^{54}$ demonstrated improved NDI and VAS neck and arm pain for patients with the Simplify Disc. Two-level use studies with the Simplify Disc have completed patient enrollment and are in the investigational pipeline for approval.

\section{Potential Complications}

Possible complications with cervical disc arthroplasty include heterotopic ossification, subsidence or migration, device wear and tear, and adjacentsegment disease. ${ }^{55}$ Recent evidence continues to report low rates of reoperation at both the index and adjacent levels. ${ }^{29,30,33,45,56-58}$ Past reports report a broad range $(7.3 \%$ to $69.2 \%)$ for heterotopic ossification rate. ${ }^{59-61}$ In a meta-analysis evaluating adverse events of total disc replacements, Anderson et $\mathrm{al}^{62}$ reported that there were no statistical differences in dysphagia, heterotopic ossification, or overall incidence of neurologic deterioration between the cervical disc arthroplasty group and ACDF group. The authors also reported that the cTDR group had a lower relative risk of surgically related neurologic events and secondary surgeries compared to ACDFs. ${ }^{62}$

\section{LUMBAR TOTAL DISC REPLACEMENT}

\section{Historical Background}

The first use of lumbar total disc replacement dates back to the 1960s. ${ }^{12,63}$ The first model of the Charité device was developed in the 1980s and subsequent models received FDA approval in $2004 .{ }^{64}$ Initial studies of this device reported improved clinical and radiographic success compared to fusion. ${ }^{65-67}$ Currently, the activL Artificial disc (Aesculap Implant Systems) and the Prodisc-L (Centinel Spine) are the only 2 commercially available FDA-approved devices. Other lumbar devices had completed premarket approval studies (Maverick, Flexicore, Kineflex, but either withdrew before FDA consideration or declined to sell commercially in the United States.

\section{Results of Current Approved Devices}

The Prodisc-L was approved by the FDA in 2006. This device consists of 3 components: upper and lower plates composed of cobalt-chrome molybdenium alloy (CoCrMo) and a monoconvex ultrahighmolecular-weight polyethylene inlay. ${ }^{68}$ Combined, these components form a spherical articulating device resembling a ball and socket joint. ${ }^{68}$ In a randomized controlled FDA IDE trial, Zigler et $\mathrm{al}^{69}$ demonstrated that patients with Prodisc-L had improved patient reported outcomes (Oswestry Disability Index [ODI], Short Form-36, and VAS pain), and neurologic success compared to patients with circumferential spinal fusion at 2-year followup. In a 5-year follow-up of the FDA IDE trial, Zigler and Delamarter ${ }^{70}$ reported that both groups maintained improved patient-reported outcomes. The authors also reported fewer secondary surgeries at the index level and acceptable range of motion in the lumbar TDR group compared to the control group. ${ }^{69}$ With an alternate analysis including additional FDA parameters, $48.1 \%$ of TDRs and $41.1 \%$ of fusions were overall statistical successes using a complex success formula. ${ }^{70}$ In an RCT FDA IDE trial for 2-level use, Delamarter et $\mathrm{al}^{71}$ reported that more patients in the lumbar TDR group $(58.8 \%)$ reached statistical overall success than the fusion group $(47.8 \%)$ at 2-year follow-up, using a similar complex success definition.

The ActivL artificial disc was approved in June 2015. This device consists of 2 metal endplates and 1 semiconstrained ultrahigh-molecular-weight polyethylene inlay. ${ }^{72}$ The polyethylene core supports anterior and posterior translational direction, potentially reducing biomechanical stress at the facet joints and adjacent levels. ${ }^{72}$ In the randomized controlled FDA IDE trial, Garcia et $\mathrm{al}^{74}$ reported that the device was noninferior to the control devices (Charite or Prodisc-L). The authors also reported improved results for return to work, radiographic success $(59 \%$ versus $43 \%)$, and ODI success $(75 \%$ versus $66 \%)$ in the activL group compared to the control group at 2-year followup. ${ }^{73}$ The activL group also had decreased serious adverse events related to the device $(12 \%$ versus 
$19 \%)$ and similar surgical reintervention rates $(2.3 \%$ versus $1.9 \%$ ) compared to controls; however, these results did not reach statistical significance. ${ }^{73}$ In addition, the activL group had improved range of motion with segmental rotation $\left(0.9^{\circ}\right.$ versus $-1.4^{\circ} ; P$ $<.01)$ and translation $(+0.6 \mathrm{~mm}$ versus $+0.2 \mathrm{~mm} ; P$ $<.001)$ but not with lateral rotation $(+0.6 \mathrm{~mm}$ versus $+0.8 \mathrm{~mm}, P=.52) .{ }^{73}$ Additionally, a greater percentage of patients with activL had an increase in disc height $(>3 \mathrm{~mm})$ than the control group $(94 \%$ versus $87 \%, P=.09) .^{73}$

Currently, there are limited reports on long-term follow-up for activL. In a randomized, controlled FDA IDE study with 5-year follow-up, Yue and Garcia $^{74}$ reported improvement in back pain severity and patient satisfaction in the activL group compared to the control group, but these results did not achieve statistical significance. The authors also reported no significant differences observed with range of motion (flexion/extension, translation, and lateral rotation) or disc height between the 2 groups. ${ }^{74}$ Comparable results relating to serious adverse events were reported in both groups $(58 \%$ versus $40 \%, P<.01){ }^{74}$

A recent meta-analysis conducted by Zigler et a $1^{75}$ of 4 RCTs with long-term follow-up demonstrated improved ODI scores, decreased risk of reoperation, and increased likelihood of patient satisfaction with TDR compared to fusion. This meta-analysis included 3 FDA IDE studies as well as 1 non-IDE prospective randomized trial outside the United States, all with 5-year follow-up. Rao et $\mathrm{al}^{76}$ conducted a meta-analysis of 7 RCTs with 2-year follow-up. Similarly, the authors reported improvements in ODI score, in addition to improved VAS score and shorter length of hospitalization. Ding et $\mathrm{al}^{77}$ reported conflicting results regarding the superiority of lumbar TDR after reviewing 5 overlapping meta-analyses. But, the authors also reported the potential of lumbar TDR as an alternative treatment to fusion based off of shortterm results.

Various devices that are approved outside of the United States have published reports with long-term follow-up. Although not a randomized controlled study, Aghayev et al $^{78}$ reported improved VAS leg and back scores and quality of life improvement (EQ-5D) in patients with lumbar TDR at 5-year follow-up. Implants included in this study were ActivL, Charité, Maverick, and Prodisc-L. The authors also reported the overall rates of complica- tions and adjacent segment degeneration as $23.4 \%$ and $10.7 \%$, respectively. ${ }^{78}$

\section{Adjacent-Segment Disease}

Past reports have attempted to further clarify the potential incidence rate and prevalence of adjacentsegment degeneration and disease after arthroplasty compared to fusion. Harrop et $\mathrm{al}^{9}$ reported a significant decrease in incidence rate of adjacentsegment degeneration ( $9 \%$ versus $34 \%$ ) and disease ( $1 \%$ versus $14 \%)$ with lumbar TDR compared to fusion. In analyzing data from a prospective multicenter study, Zigler et $\mathrm{al}^{79}$ reported fewer changes in adjacent-level degeneration in the lumbar TDR group compared to fusion $(9.2 \%$ versus $28.6 \%$ ) at 5 -year follow-up. The authors also reported a decrease in new findings of adjacentlevel degeneration $(6.7 \%$ versus $23.8 \%)$ and secondary surgery $(1.9 \%$ versus $4.0 \%)$ in the lumbar TDR group compared to fusion. ${ }^{79}$ In a metaanalysis of 13 studies, Ren et $\mathrm{al}^{80}$ also demonstrated decreased prevalence and reoperation rate in the lumbar TDR group compared to fusion for shortterm and long-term follow-up.

\section{Approval for 2-Level Use}

Multi-level lumbar disc replacement has been described in the literature since 2005, when Bertagnoli et $\mathrm{al}^{81}$ described hybrid constructs including lumbar ADR at 2 and even 3 levels. Erkan et $\mathrm{al}^{82}$ published data about the biomechanics of 2-level lumbar disc replacement in 2009. In 2011, Delamarter et $\mathrm{al}^{83}$ published the 2-year outcomes analysis of the IDE study of ProDisc-L TDR compared to circumferential arthrodesis, demonstrating maintained range of motion at both implanted levels, equivalent or better VAS and ODI scores compared to fusion patients, and statistically significantly fewer reoperations $(2.4 \%$ versus $8.2 \%, P=.0497)$ and significantly lower narcotic usage rates $(36.4 \%$ versus $61.0 \%, P=.0017$ ) in TDR versus fusion patients.

Published positive outcomes in smaller cohorts of 2-level lumbar TDR in military personnel with 28month follow-up ${ }^{84}$ and in single-site 2-level IDE patients at 9- to 10 -year follow-up ${ }^{85}$ were followed by an examination of secondary surgery rates at 5year follow-up in the 229 patients from the initial ProDisc-L 2-level IDE study by Radcliff et al, ${ }^{86}$ showing that "fewer patients underwent secondary 
surgery at adjacent levels in the TDR patients compared with the fusion controls."

In April 2020, the FDA approved expanded use of ProDisc-L "to include treatment of up two consecutive lumbar spinal sections (levels) from L3-S1." ${ }^{87}$ The indications were expanded to patients who "Have a condition in which pain is caused by wear-and-tear on a spinal disc (DDD) at one or two consecutive levels in the lumbar spine." 87

\section{Potential Complications}

Implant-related complications can include collapse, subsidence, or dislocation. ${ }^{78,88,89}$ Additional concerns with lumbar arthroplasty include approach-related complications, osteolysis secondary to polyethylene wear, heterotopic ossification and reoperation at the index or adjacent level. ${ }^{90}$ Past reports demonstrate low or similar rates of reoperation with lumbar TDR compared to fusion. ${ }^{69,70,73,75,76,91}$ In a meta-analysis conducted by Hiratzka et al, ${ }^{92}$ patients in the lumbar fusion group had a 2-fold increased risk of adverse events compared with lumbar TDR with 2-year follow-up but the relative risk remained stable at 5-year follow-up. Additionally, these pooled data were from a limited number of RCTs due to a lack of consistency with reporting and describing adverse events in the various trials. ${ }^{92}$

\section{CONCLUSION}

Currently, there is compelling level I and II evidence with long-term follow-up that supports the use of cervical and lumbar TDR as a viable alternative to fusion procedures for appropriately selected patients. Those with exclusions per FDA labelling should not be considered for arthroplasty.

Although some of these data are derived from industry sponsored trials, there are multiple layers of independent and governmental oversight, as well as peer review prior to publication. Recent evidence and comparison with meta-analyses continue to demonstrate positive outcomes and benefits over time, even with with expanded 2-level use in the cervical spine. Studies now following patients out to 5 to 10 years continue to show positive results for these devices.

Based on the above review of the available evidence-based scientific literature (much of it level I), the International Society for the Advancement of Spine Surgery, as a global organization of spine surgery professionals, strongly supports both cervical and lumbar total disc replacements, including multi-level use as approved by the FDA, as safe and effective treatment alternatives to fusion in appropriately selected patients. FDA study guidelines and labelling regarding inclusion and exclusion criteria should be followed for use, as supported by a strong published database.

\section{REFERENCES}

1. Hoy DG, Protani M, De R, Buchbinder R. The epidemiology of neck pain. Best Pract Res Clin Rheumatol. 2010;24(6):783-792. doi:10.1016/j.berh.2011.01.019

2. Kong L, Tian W, Cao P, Wang H, Zhang B, Shen Y. Predictive factors associated with neck pain in patients with cervical disc degeneration. Medicine (Baltimore). 2017;96(43):e8447. doi:10.1097/MD.0000000000008447

3. Hoy D, Brooks P, Blyth F, Buchbinder R. The epidemiology of low back pain. Best Pract Res Clin Rheumatol. 2010;24(6):769-781. doi:10.1016/j.berh.2010.10.002

4. Martin BI, Deyo RA, Mirza SK, et al. Expenditures and health status among adults with back and neck problems. JAMA. 2008;299(6):656-664. doi:10.1001/jama.299.6.656

5. Katz JN. Lumbar disc disorders and low-back pain: socioeconomic factors and consequences. J Bone Joint Surg Am. 2006;88(suppl 2):21-24. doi:10.2106/JBJS.E.01273

6. Hilibrand AS, Carlson GD, Palumbo MA, Jones PK, Bohlman HH. Radiculopathy and myelopathy at segments adjacent to the site of a previous anterior cervical arthrodesis. $J$ Bone Joint Surg Am. 1999;81(4):519-528. doi:10.2106/ 00004623-199904000-00009

7. Goffin J, Van Calenbergh F, van Loon J, et al. Intermediate follow-up after treatment of degenerative disc disease with the Bryan cervical disc prosthesis: single-level and bi-level. Spine. 2003;28(24):2673-2678. doi:10.1097/01.BRS 0000099392.90849.AA

8. Katsuura A, Hukuda S, Saruhashi Y, Mori K. Kyphotic malalignment after anterior cervical fusion is one of the factors promoting the degenerative process in adjacent intervertebral levels. Eur Spine J. 2001;10(4):320-324. doi:10.1007/ s005860000243

9. Harrop JS, Youssef JA, Maltenfort M, et al. Lumbar adjacent segment degeneration and disease after arthrodesis and total disc arthroplasty. Spine. 2008;33(15):1701-1707. doi:10. 1097/BRS.0b013e31817bb956

10. Park P, Garton HJ, Gala VC, Hoff JT, McGillicuddy JE. Adjacent segment disease after lumbar or lumbosacral fusion: review of the literature. Spine. 2004;29(17):1938-1944.

11. Lee CS, Hwang CJ, Lee S-W, et al. Risk factors for adjacent segment disease after lumbar fusion. Eur Spine J. 2009;18(11):1637-1643. doi:10.1007/s00586-009-1060-3

12. Fernström U. Arthroplasty with intercorporal endoprothesis in herniated disc and in painful disc. Acta Chir Scand Suppl. 1966;357:154-159.

13. Food and Drug Administration. Summary of safety and effectiveness data (SSED) M6-C artificial cervical disc. https:// www.accessdata.fda.gov/cdrh_docs/pdf17/P170036B.pdf. Accessed June 2, 2019.

14. Mummaneni PV, Burkus JK, Haid RW, Traynelis VC, 
Zdeblick TA. Clinical and radiographic analysis of cervical disc arthroplasty compared with allograft fusion: a randomized controlled clinical trial. J Neurosurg Spine. 2007;6(3):198-209. doi:10.3171/spi.2007.6.3.198

15. Murrey D, Janssen M, Delamarter R, et al. Results of the prospective, randomized, controlled multicenter Food and Drug Administration investigational device exemption study of the ProDisc-C total disc replacement versus anterior discectomy and fusion for the treatment of 1-level symptomatic cervical disc disease. Spine J. 2009;9(4):275-286. doi:10.1016/j.spinee. 2008.05.006

16. Heller JG, Sasso RC, Papadopoulos SM, et al. Comparison of BRYAN cervical disc arthroplasty with anterior cervical decompression and fusion: clinical and radiographic results of a randomized, controlled, clinical trial. Spine (Phila Pa 1976). 2009;34(2):101-107. doi:10.1097/BRS. 0b013e31818ee263

17. Vaccaro A, Beutler W, Peppelman W, et al. Clinical outcomes with selectively constrained SECURE-C cervical disc arthroplasty: two-year results from a prospective, randomized, controlled, multicenter investigational device exemption study. Spine. 2013;38(26):2227-2239. doi:10.1097/BRS. 0000000000000031

18. Phillips FM, Lee JYB, Geisler FH, et al. A prospective, randomized, controlled clinical investigation comparing PCM cervical disc arthroplasty with anterior cervical discectomy and fusion. 2-year results from the US FDA IDE clinical trial. Spine. 2013;38(15):E907-918. doi:10.1097/BRS. 0b013e318296232f

19. Hisey MS, Bae HW, Davis R, et al. Multi-center, prospective, randomized, controlled investigational device exemption clinical trial comparing Mobi-C cervical artificial disc to anterior discectomy and fusion in the treatment of symptomatic degenerative disc disease in the cervical spine. Int J Spine Surg. 2014;8:7. doi:10.14444/1007

20. Davis RJ, Kim KD, Hisey MS, et al. Cervical total disc replacement with the Mobi-C cervical artificial disc compared with anterior discectomy and fusion for treatment of 2-level symptomatic degenerative disc disease: a prospective, randomized, controlled multicenter clinical trial: clinical article. $J$ Neurosurg Spine. 2013;19(5):532-545. doi:10.3171/2013.6. SPINE12527

21. Gornet MF, Burkus JK, Shaffrey ME, Argires PJ, Nian H, Harrell FE. Cervical disc arthroplasty with PRESTIGE LP disc versus anterior cervical discectomy and fusion: a prospective, multicenter investigational device exemption study. $J$ Neurosurg Spine. 2015;23(5):558-573. doi:10.3171/2015.1. SPINE14589

22. McAfee PC, Reah C, Gilder K, Eisermann L, Cunningham B. A meta-analysis of comparative outcomes following cervical arthroplasty or anterior cervical fusion: results from 4 prospective multicenter randomized clinical trials and up to 1226 patients. Spine. 2012;37(11):943-952. doi:10.1097/BRS. 0b013e31823da169

23. Upadhyaya CD, Wu J-C, Trost G, et al. Analysis of the three United States Food and Drug Administration investigational device exemption cervical arthroplasty trials. J Neurosurg Spine. 2012;16(3):216-228. doi:10.3171/2011.6.SPINE10623

24. Quan GM, Vital J-M, Hansen S, Pointillart V. Eightyear clinical and radiological follow-up of the Bryan cervical disc arthroplasty. Spine. 2011;36(8):639-646. doi:10.1097/BRS. 0b013e3181dc9b51
25. Burkus JK, Haid RW, Traynelis VC, Mummaneni PV. Long-term clinical and radiographic outcomes of cervical disc replacement with the Prestige disc: results from a prospective randomized controlled clinical trial: presented at the 2009 Joint Spine Section Meeting. J Neurosurg Spine. 2010;13(3):308-318. doi:10.3171/2010.3.SPINE09513

26. Coric D, Kim PK, Clemente JD, Boltes MO, Nussbaum M, James S. Prospective randomized study of cervical arthroplasty and anterior cervical discectomy and fusion with long-term follow-up: results in 74 patients from a single site: presented at the 2012 Joint Spine Section Meeting. J Neurosurg Spine. 2013;18(1):36-42. doi:10.3171/2012.9.SPINE12555

27. Zigler J, Delamarter R, Murrey D, Spivak J, Janssen M. ProDisc-C and anterior cervical discectomy and fusion as surgical treatment for single-level cervical symptomatic degenerative disc disease: five-year results of a Food and Drug Administration study. Spine. 2013;38(3):203-209. doi:10.1097/ BRS.0b013e318278eb38

28. Delamarter RB, Murrey D, Janssen ME, et al. Results at 24 months from the prospective, randomized, multicenter Investigational Device Exemption trial of ProDisc-C versus anterior cervical discectomy and fusion with 4-year follow-up and continued access patients. SAS J. 2010;4(4):122-128. doi:10.1016/j.esas.2010.09.001

29. Janssen ME, Zigler JE, Spivak JM, Delamarter RB, Darden BV, Kopjar B. ProDisc-C total disc replacement versus anterior cervical discectomy and fusion for single-level symptomatic cervical disc disease: seven-year follow-up of the prospective randomized U.S. Food and Drug Administration Investigational Device Exemption study. J Bone Joint Surg Am. 2015;97(21):1738-1747. doi:10.2106/JBJS.N.01186

30. Gornet MF, Burkus JK, Shaffrey ME, Schranck FW, Copay AG. Cervical disc arthroplasty: 10-year outcomes of the Prestige LP cervical disc at a single level. J Neurosurg Spine. 2019;1(aop):1-9. doi:10.3171/2019.2.SPINE1956

31. Lavelle W, Riew K, Levi A, Florman J. Ten-year outcomes of cervical disc replacement with the BRYAN cervical disc: results from a prospective, randomized, controlled clinical trial. Spine. 2019;44(9):601-608. doi:10.1097/BRS. 0000000000002907

32. Phillips FM, Geisler FH, Gilder KM, Reah C, Howell KM, McAfee PC. Long-term outcomes of the US FDA IDE prospective, randomized controlled clinical trial comparing PCM cervical disc arthroplasty with anterior cervical discectomy and fusion. Spine. 2015;40(10):674-683. doi:10.1097/BRS. 0000000000000869

33. Hisey MS, Zigler JE, Jackson R, et al. Prospective, randomized comparison of one-level Mobi-C cervical total disc replacement vs. anterior cervical discectomy and fusion: results at 5-year follow-up. Int J Spine Surg. 2016;10:10. doi:10.14444/ 3010

34. Burkus JK, Traynelis VC, Haid RW Jr, Mummaneni PV. Clinical and radiographic analysis of an artificial cervical disc: 7-year follow-up from the Prestige prospective randomized controlled clinical trial: clinical article. J Neurosurg Spine. 2014;21(4):516-528. doi:10.3171/2014.6.SPINE13996

35. Vaccaro A, Beutler W, Peppelman W, et al. Long-term clinical experience with selectively constrained SECURE-C cervical artificial disc for 1-level cervical disc disease: results from seven-year follow-up of a prospective, randomized, controlled Investigational Device Exemption clinical trial. Int J Spine Surg. 2018;12(3):377-387. doi:10.14444/5044 
36. Radcliff K, Davis RJ, Hisey MS, et al. Long-term evaluation of cervical disc arthroplasty with the Mobi-C(C) cervical disc: a randomized, prospective, multicenter clinical trial with seven-year follow-up. Int J Spine Surg. 2017;11(4):31. doi: $10.14444 / 4031$

37. Gao F, Mao T, Sun W, et al. An updated meta-analysis comparing artificial cervical disc arthroplasty (CDA) versus anterior cervical discectomy and fusion (ACDF) for the treatment of cervical degenerative disc disease (CDDD). Spine. 2015;40(23):1816. doi:10.1097/BRS.0000000000001138

38. Zhang Y, Liang C, Tao Y, et al. Cervical total disc replacement is superior to anterior cervical decompression and fusion: a meta-analysis of prospective randomized controlled trials. PloS One. 2015;10(3):e0117826. doi:10.1371/journal. pone. 0117826

39. Kelly MP, Eliasberg CD, Riley MS, Ajiboye RM, SooHoo NF. Reoperation and complications after anterior cervical discectomy and fusion and cervical disc arthroplasty: a study of 52,395 cases. Eur Spine J. 2018;27(6):1432-1439. doi:10.1007/s00586-018-5570-8

40. Verma K, Gandhi SD, Maltenfort M, et al. Rate of adjacent segment disease in cervical disc arthroplasty versus single-level fusion: meta-analysis of prospective studies. Spine. 2013;38(26):2253-2257. doi:10.1097/BRS.0000000000000052

41. Shriver MF, Lubelski D, Sharma AM, Steinmetz MP, Benzel EC, Mroz TE. Adjacent segment degeneration and disease following cervical arthroplasty: a systematic review and meta-analysis. Spine J. 2016;16(2):168-181. doi:10.1016/j. spinee.2015.10.032

42. Zhu Y, Zhang B, Liu H, Wu Y, Zhu Q. Cervical disc arthroplasty versus anterior cervical discectomy and fusion for incidence of symptomatic adjacent segment disease: a metaanalysis of prospective randomized controlled trials. Spine. 2016;41(19):1493-1502. doi:10.1097/BRS.0000000000001537

43. Luo J, Gong M, Huang S, Yu T, Zou X. Incidence of adjacent segment degeneration in cervical disc arthroplasty versus anterior cervical decompression and fusion meta-analysis of prospective studies. Arch Orthop Trauma Surg. 2015;135(2):155-160. doi:10.1007/s00402-014-2125-2

44. Davis RJ, Nunley PD, Kim KD, et al. Two-level total disc replacement with Mobi-C cervical artificial disc versus anterior discectomy and fusion: a prospective, randomized, controlled multicenter clinical trial with 4-year follow-up results. J Neurosurg Spine. 2015;22(1):15-25. doi:10.3171/ 2014.7.SPINE13953

45. Radcliff K, Coric D, Albert T. Five-year clinical results of cervical total disc replacement compared with anterior discectomy and fusion for treatment of 2-level symptomatic degenerative disc disease: a prospective, randomized, controlled, multicenter investigational device exemption clinical trial. J Neurosurg Spine. 2016;25(2):213-224. doi:10.3171/2015. 12.SPINE15824

46. Bae HW, Kim KD, Nunley PD, et al. Comparison of clinical outcomes of 1- and 2-level total disc replacement: fouryear results from a prospective, randomized, controlled, multicenter IDE clinical trial. Spine. 2015;40(11):759-766. doi:10.1097/BRS.0000000000000887

47. Gornet MF, Lanman TH, Burkus JK, et al. Cervical disc arthroplasty with the Prestige LP disc versus anterior cervical discectomy and fusion, at 2 levels: results of a prospective, multicenter randomized controlled clinical trial at 24 months. $J$
Neurosurg Spine. 2017;26(6):653-667. doi:10.3171/2016.10. SPINE16264

48. Lanman TH, Burkus JK, Dryer RG, Gornet MF, McConnell J, Hodges SD. Long-term clinical and radiographic outcomes of the Prestige LP artificial cervical disc replacement at 2 levels: results from a prospective randomized controlled clinical trial. J Neurosurg Spine. 2017;27(1):7-19. doi:10.3171/ 2016.11.SPINE16746

49. Lauryssen C, Coric D, Dimmig T, Musante D, Ohnmeiss DD, Stubbs HA. Cervical total disc replacement using a novel compressible prosthesis: results from a prospective Food and Drug Administration-regulated feasibility study with 24-month follow-up. Int J Spine Surg. 2012;6(1):71-77. doi:10.1016/j.ijsp. 2012.02.001

50. Patwardhan AG, Tzermiadianos MN, Tsitsopoulos PP, et al. Primary and coupled motions after cervical total disc replacement using a compressible six-degree-of-freedom prosthesis. Eur Spine J. 2012;21(suppl 5):618-629. doi:10.1007/ s00586-010-1575-7

51. Reyes-Sanchez A, Miramontes V, Olivarez LMR, Aquirre AA, Quiroz AO, Zarate-Kalfopulos B. Initial clinical experience with a next-generation artificial disc for the treatment of symptomatic degenerative cervical radiculopathy. $S A S$ J. 2010;4(1):9-15. doi:10.1016/j.esas.2010.01.002

52. Thomas S, Willems K, Van den Daelen L, Linden $\mathrm{P}$, Ciocci M-C, Bocher P. The M6-C cervical disk prosthesis: first clinical experience in 33 patients. Clin Spine Surg. 2016;29(4):E182-187. doi:10.1097/BSD.0000000000000025

53. Phillips FM, Coric D, Sasso R, et al. Prospective, multicenter clinical trial comparing M6-C compressible six degrees of freedom cervical disc with anterior cervical discectomy and fusion for the treatment of single-level degenerative cervical radiculopathy: 2-year results of an FDA investigational device exemption study [published online ahead of print October 20, 2020]. Spine J. doi:10.1016/j.spinee.2020. 10.014

54. Geisler FH, Maislin DG, Keenan BT, Maislin G. Oneyear NDI and VAS outcomes from the single-level PEEK-onceramic SimplifyTM Disc FDA IDE trial. J Spine Neurosurg. 2019;8(2). doi:10.4172/2325-9701.1000320

55. Leven D, Meaike J, Radcliff K, Qureshi S. Cervical disc replacement surgery: indications, technique, and technical pearls. Curr Rev Musculoskelet Med. 2017;10(2):160-169. doi:10.1007/s12178-017-9398-3

56. Bhashyam N, De la Garza Ramos R, Nakhla J, et al. Thirty-day readmission and reoperation rates after single-level anterior cervical discectomy and fusion versus those after cervical disc replacement. Neurosurg Focus. 2017;42(2):E6. doi:10.3171/2016.11.FOCUS16407

57. Chang K-E, Pham MH, Hsieh PC. Adjacent segment disease requiring reoperation in cervical total disc arthroplasty: a literature review and update. $J$ Clin Neurosci Off $J$ Neurosurg Soc Australas. 2017;37:20-24. doi:10.1016/j.jocn.2016.10.047

58. Jackson RJ, Davis RJ, Hoffman GA, et al. Subsequent surgery rates after cervical total disc replacement using a MobiC cervical disc prosthesis versus anterior cervical discectomy and fusion: a prospective randomized clinical trial with 5-year follow-up. J Neurosurg Spine. 2016;24(5):734-745. doi:10.3171/ 2015.8.SPINE15219

59. Chen J, Wang X, Bai W, Shen X, Yuan W. Prevalence of heterotopic ossification after cervical total disc arthroplasty: a 
meta-analysis. Eur Spine J. 2012;21(4):674-680. doi:10.1007/ s00586-011-2094-X

60. Yi S, Kim KN, Yang MS, et al. Difference in occurrence of heterotopic ossification according to prosthesis type in the cervical artificial disc replacement. Spine. 2010;35(16):15561561. doi:10.1097/BRS.0b013e3181c6526b

61. Mehren C, Suchomel P, Grochulla F, et al. Heterotopic ossification in total cervical artificial disc replacement. Spine. 2006;31(24):2802-2806. doi:10.1097/01.brs.0000245852.70594. d5

62. Anderson PA, Nassr A, Currier BL, et al. Evaluation of adverse events in total disc replacement: a meta-analysis of FDA summary of safety and effectiveness data. Glob Spine J. 2017;7(suppl 1):76S-83S. doi:10.1177/2192568216688195

63. Salzmann SN, Plais N, Shue J, Girardi FP. Lumbar disc replacement surgery-successes and obstacles to widespread adoption. Curr Rev Musculoskelet Med. 2017;10(2):153-159. doi:10.1007/s12178-017-9397-4

64. US Food and Drug Administration. Premarket approval. https:/www.accessdata.fda.gov/scripts/cdrh/cfdocs/cfpma/ pma.cfm?id=P170036. Accessed June 2, 2019.

65. McAfee PC, Cunningham B, Holsapple G, et al. A prospective, randomized, multicenter Food and Drug Administration investigational device exemption study of lumbar total disc replacement with the CHARITE artificial disc versus lumbar fusion: part II: evaluation of radiographic outcomes and correlation of surgical technique accuracy with clinical outcomes. Spine. 2005;30(14):1576-1583; discussion E388-390.

66. Guyer RD, McAfee PC, Banco RJ, et al. Prospective, randomized, multicenter Food and Drug Administration investigational device exemption study of lumbar total disc replacement with the CHARITE artificial disc versus lumbar fusion: five-year follow-up. Spine J. 2009;9(5):374-386. doi:10. 1016/j.spinee.2008.08.007

67. Blumenthal S, McAfee PC, Guyer RD, et al. A prospective, randomized, multicenter Food and Drug Administration investigational device exemptions study of lumbar total disc replacement with the CHARITE artificial disc versus lumbar fusion: part I: evaluation of clinical outcomes. Spine. 2005;30(14):1565-1575; discussion E387-391.

68. Bertagnoli R, Habbicht $H$. The ProDisc-L lumbar prosthesis. Interact Surg. 2008;3(4):209-213. doi:10.1007/ s11610-007-0042-6

69. Zigler J, Delamarter R, Spivak JM, et al. Results of the prospective, randomized, multicenter Food and Drug Administration investigational device exemption study of the ProDisc$\mathrm{L}$ total disc replacement versus circumferential fusion for the treatment of 1-level degenerative disc disease. Spine. 2007;32(11):1155-1162; discussion 1163. doi:10.1097/BRS. 0b013e318054e 377

70. Zigler JE, Delamarter RB. Five-year results of the prospective, randomized, multicenter, Food and Drug Administration investigational device exemption study of the ProDiscL total disc replacement versus circumferential arthrodesis for the treatment of single-level degenerative disc disease. $J$ Neurosurg Spine. 2012;17(6):493-501. doi:10.3171/2012.9. SPINE11498

71. Delamarter R, Zigler JE, Balderston RA, Cammisa FP, Goldstein JA, Spivak JM. Prospective, randomized, multicenter Food and Drug Administration investigational device exemption study of the ProDisc-L total disc replacement compared with circumferential arthrodesis for the treatment of two-level lumbar degenerative disc disease: results at twenty-four months. J Bone Joint Surg Am. 2011;93(8):705-715. doi:10.2106/JBJS.I. 00680

72. Yue JJ, Garcia R, Miller LE. The activL ${ }^{\circledR}$ artificial disc: a next-generation motion-preserving implant for chronic lumbar discogenic pain. Med Devices Auckl NZ. 2016;9:75-84. doi:10.2147/MDER.S102949

73. Garcia RJ, Yue JJ, Blumenthal S, et al. Lumbar total disc replacement for discogenic low back pain: two-year outcomes of the activL multicenter randomized controlled IDE clinical trial. Spine. 2015;40(24):1873. doi:10.1097/BRS. 0000000000001245

74. Yue JJ, Garcia R. Five-year results of a randomized controlled trial for lumbar artificial discs in single-level degenerative disc disease. Spine J. 2017;17(10):S70. doi:10. 1016/j.spinee.2017.07.047

75. Zigler J, Gornet MF, Ferko N, Cameron C, Schranck FW, Patel L. Comparison of lumbar total disc replacement with surgical spinal fusion for the treatment of single-level degenerative disc disease: a meta-analysis of 5-year outcomes from randomized controlled trials. Glob Spine J. 2018;8(4):413-423. doi: $10.1177 / 2192568217737317$

76. Rao M-J, Cao S-S. Artificial total disc replacement versus fusion for lumbar degenerative disc disease: a metaanalysis of randomized controlled trials. Arch Orthop Trauma Surg. 2014;134(2):149-158. doi:10.1007/s00402-013-1905-4

77. Ding F, Jia Z, Zhao Z, et al. Total disc replacement versus fusion for lumbar degenerative disc disease: a systematic review of overlapping meta-analyses. Eur Spine J. 2017;26(3):806-815. doi:10.1007/s00586-016-4714-y

78. Aghayev E, Etter C, Bärlocher C, et al. Five-year results of lumbar disc prostheses in the SWISSspine registry. Eur Spine J. 2014;23(10):2114-2126. doi:10.1007/s00586-014-3418-4

79. Zigler JE, Glenn J, Delamarter RB. Five-year adjacentlevel degenerative changes in patients with single-level disease treated using lumbar total disc replacement with ProDisc-L versus circumferential fusion. $J$ Neurosurg Spine. 2012;17(6):504-511. doi:10.3171/2012.9.SPINE11717

80. Ren C, Song Y, Liu L, Xue Y. Adjacent segment degeneration and disease after lumbar fusion compared with motion-preserving procedures: a meta-analysis. Eur J Orthop Surg Traumatol. 2014;24(1):245-253. doi:10.1007/s00590-0141445-9

81. Bertagnoli R, Tropiano P, Zigler J, Karg A, Voigt S. Hybrid constructs. Orthop Clin North Am. 2005;36(3):379-388.

82. Erkan S, Rivera Y, Wu C, Mehbod AA, Transfeldt EE. Biomechanical comparison of a two-level Maverick disc replacement with a hybrid one-level disc replacement and onelevel anterior lumbar interbody fusion. Spine J. 2009;9(10):830 835 .

83. Delamarter R, Zigler JE, Balderston RA, et al. Prospective, randomized, multicenter Food and Drug Administration investigational device exemption study of the ProDiscL Total Disc Replacement compared with circumferential arthrodesis for the treatment of two-level lumbar degenerative disc disease: results at twenty-four months. J Bone Joint Surg. 2011;93(8):705-715.

84. Petilon J, Roth J, Hardenbrook M. Results of lumbar total disc arthroplasty in military personnel. J Spine Disord Tech. 2011;24(5):297-301.

85. Balderston JR, Gertz ZM, McIntosh T, Balderston RA. Long-term outcomes of 2-level total disc replacement using 
ProDisc-L: nine- to 10-year follow-up. Spine (Phila Pa 1976). 2014;39(11):906-910.

86. Radcliff K, Spivak J, Darden B 2nd, Janssen M, Bernard T, Zigler J. Five-year reoperation rates of 2-level lumbar total disk replacement versus fusion: results of a prospective, randomized clinical trial. Clin Spine Surg. 2018;31(1):37-42.

87. U.S. Food and Drug Administration. The prodisc L total disc replacement - P050010/S020. https://www.fda.gov/medicaldevices/recently-approved-devices/prodisc-1-total-discreplacement-p050010s020. Accessed December 13, 2020.

88. Scott-Young MN, Lee MJ, Nielsen DEA, Magno CL, Kimlin KR, Mitchell EO. Clinical and radiological mid-term outcomes of lumbar single-level total disc replacement. Spine. 2018;43(2):105-113. doi:10.1097/BRS.0b013e3182345aa2

89. Putzier M, Funk JF, Schneider SV, et al. Charité total disc replacement - clinical and radiographical results after an average follow-up of 17 years. Eur Spine J. 2006;15(2):183-195. doi:10.1007/s00586-005-1022-3

90. Siepe CJ, Heider F, Wiechert K, Hitzl W, Ishak B, Mayer MH. Mid- to long-term results of total lumbar disc replacement: a prospective analysis with 5- to 10-year followup. Spine J. 2014;14(8):1417-1431. doi:10.1016/j.spinee.2013. 08.028

91. Eliasberg CD, Kelly MP, Ajiboye RM, SooHoo NF.
Complications and rates of subsequent lumbar surgery following lumbar total disc arthroplasty and lumbar fusion. Spine. 2016;41(2):173-181. doi:10.1097/BRS.0000000000001180

92. Hiratzka JR, Rastegar F, Contag AG, Norvell D, Anderson PA, Hart RA. Adverse event recording and reporting in clinical trials comparing lumbar disk replacement with lumbar fusion: a systematic review. Glob Spine J. 2015;5(6):486-495. doi:10.1055/s-0035-1567835

Corresponding Author: Frank M. Phillips, MD, Midwest Orthopaedics at Rush, Rush University Medical Center, 1611 W Harrison St, Suite 300, Chicago, IL 60612-4861. Email: frank.phillips@ rushortho.com.

Published 26 February 2021

This manuscript is generously published free of charge by ISASS, the International Society for the Advancement of Spine Surgery. Copyright (C) 2021 ISASS. To see more or order reprints or permissions, see http://ijssurgery.com. 